\title{
Tests of low-temperature properties of rope lubricant
}

\author{
V. Yu. Sholom ${ }^{\dagger, 1,2}$, O. L. Kramer ${ }^{1,2}$, V.P. Golovin ${ }^{1,2}$, A. N. Abramov ${ }^{1,2}$, R. F. Vagapov ${ }^{2}$ \\ †rosoil@rosoil.ru
}

${ }^{1}$ Ufa State Aviation Technical University, Ufa, 450000, Russia

${ }_{2}^{2}$ "Technopark KhTTs UAI-ROSOIL”, Ufa, 450057, Russia

\begin{abstract}
The paper presents the results of a comparative analysis of methods for testing the low-temperature properties of rope lubricants. Studies have shown that the designation of the temperature range for the use of the rope must be carried out taking into account the low-temperature properties of the rope lubricant used in its manufacture, determined in accordance with GOST 20458-89. The use for these purposes of the instructions of GOST 11507-78 or EN 12593:2007, which are intended for testing the low-temperature properties of bitumen, can lead to a significant unjustified reduction in the service life of the rope, since the test method according to the European standard provides for static loading of the sample film applied to the steel plate during its bending, and according to the Russian state standard, shock loading of the sample is provided, which, according to the authors, is closer to the real operating conditions. It is shown that the maximum effect of increasing the wear resistance of the rope at low temperatures is given by the lubricants having the best low-temperature properties determined by the standard method, which is confirmed by the complete correlation of the comparative results of testing the low-temperature properties and wear resistance of the rope at low temperatures. The authors have experimentally confirmed that the highest wear resistance of the rope at low temperatures is provided by lubricants, which have the best low-temperature properties, determined in accordance with GOST 20458-89. It has been established that lubricants, which have unsatisfactory lowtemperature properties, significantly reduce the service life of ropes that are operated at low temperatures, in some cases even with respect to an unlubricated rope. The authors suggest that at low temperatures the components of the lubricant crystallize, the resulting crystals play the role of abrasive elements contributing to accelerated abrasive wear of the wire surfaces.
\end{abstract}

Keywords: rope, wear resistance, rope lubricant, running machine, climate chamber, low-temperature properties.

УДК: 620.199

\section{Методы испытаний низкотемпературных свойств смазочных материалов для канатов}

\author{
Шолом В. Ю. ${ }^{\dagger, 1,2}$, Крамер О. Л., ${ }^{1,2}$, Головин В. П. ${ }^{1,2}$, Абрамов А.Н. ${ }^{1,2}$, Вагапов Р. Ф. \\ ${ }^{1}$ Уфимский государственный авиационный технический университет, Уфа, 450000, Россия \\ ${ }^{2}$ «Технопарк ХТЦ УАИ-РОСОЙЛ», Уфа, 450057, Россия
}

В работе представлен сравнительный анализ методов испытаний низкотемпературных свойств канатных смазочных материалов (СМ). Исследования показали, что назначение температурного диапазона применения каната необходимо производить с учетом низкотемпературных свойств канатного СМ, использованного при его изготовлении, определяемых в соответствии с ГОСТ 20458-89. Использование для этих целей указаний ГОСТ 11507-78 или EN 12593:2007, которые предназначены для испытаний низкотемпературных свойств битумов, может привести к существенному неоправданному сокращению срока службы каната, так как методика испытаний по европейскому стандарту предусматривает статическое нагружение пленки образца, нанесенного на стальную пластинку при ее изгибе, а по российскому государственному стандарту предусматривается ударное нагружение образца, что, по мнению авторов, ближе к реальным условиям эксплуатации. Показано, что максимальный эффект повышения износостойкости каната при низких температурах дают СМ, имеющие наилучшие низкотемпературные свойства, определенные по стандартной методике, что подтверждается полной корреляцией сравнительных результатов испытаний низкотемпературных свойств и износостойкости каната при низких температурах. Авторами статьи экспериментально подтверждено, что наиболее высокую износостойкость каната при низких температурах обеспечивают СМ, имеющие наилучшие низкотемпературные свойства, определяемые по ГОСТ $20458-89$. Установлено, что СМ, имеющие неудовлетворительные низкотемпературные свойства, существенно сокращают 
срок службы канатов, которые эксплуатируются при низких температурах, в отдельных случаях даже по отношению к не смазанному канату. Авторами высказано предположение, что при низких температурах компоненты смазочного материала кристаллизуется, образующиеся кристаллы выполняют роль абразивных элементов, способствующих ускоренному абразивному износу поверхностей проволок.

Ключевые слова: канат, износостойкость, канатный смазочный материал, пробежная машина, климатическая камера, низкотемпературные свойства.

Стальные проволочные канаты широко используются практически во всех отраслях промышленности в качестве гибкой тяги в грузоподъемных транспортных машинах, а также в качестве несущих конструкций, нагруженных на растяжение. Главным требованием к стальным канатам является высокая надежность в течение всего срока эксплуатации, поскольку его повреждение и разрыв грозят как минимум выходом из строя технологического оборудования, а как максимум, угрожают жизни и здоровью людей в зависимости от назначения механизма или конструкции, в которых используется канат [1-5].

Существенное влияние на рабочую долговечность канатов оказывает их смазка. Канат подвергается смазке в процессе изготовления, при хранении и эксплуатации. При изготовлении смазываются и сердечник, и отдельные проволоки. Сердечник перед канатовьющей машиной проходит через ванну с разогретым консистентным смазочным материалом (CM). Проволоки смазываются или в мотках, или в процессе свивки прядей путем подачи разогретого СМ в конус свивки перед зажимным устройством.

Смазка наружной поверхности каната производится перед намоткой его на приемную бухту. В связи с большим разнообразием внешних условий работы стальных канатов, на грузоподъемных машинах устанавливаются различные периодичности смазывания канатов и подбираются соответствующие смазочные материалы. При повторной смазке необходимо обеспечить сплошной слой СМ, так как наличие несмазанных мест может вызвать точечную коррозию, что приводит к уменьшению рабочей долговечности каната. Испытания показывают, что срок службы смазанного каната выше, чем несмазанного более чем на $40 \%$ [5-7].

На российских металлургических предприятиях, производящих стальные канаты, низкотемпературные свойства канатных СМ определяли по методике, преду- смотренной ГОСТ 20458-89 «Смазка Торсиол-55. Технические условия». Производители канатных СМ также использовали эту методику при определении температурного диапазона применения своей продукции в составе каната [8].

В последние годы на российском рынке появились современные канатные СМ зарубежного производства, нередко существенно превосходящие отечественные по техническому ресурсу, которые используются ведущими производителями канатов.

Следует отметить, что на технический ресурс каната (срок службы до частичного или полного разрушения) помимо смазки существенно влияют механические свойства материала проволок и сердечника, конструкция и технология свивки прядей и каната [9-15].

В нормативно-технической документации на зарубежные смазочные материалы, применяющиеся при производстве канатов, низкотемпературные свойства канатных СМ определяются по европейскому региональному стандарту EN 12593:2007, который идентичен российскому ГОСТ 11507-78 «Битум и битуминозные вяжущие. Метод определения температуры хрупкости по Фраасу» [16].

Результаты сравнительных лабораторных испытаний низкотемпературных свойств различных канатных СМ по различным методикам приведены в Табл. 1.

Сопоставление данных Табл. 1, полученных авторами при испытаниях в лабораториях «Технопарка ХТЦ УАИ - РОСОЙЛ позволяет авторам работы сделать вывод, что использование стандарта EN 12593:2007 при определении низкотемпературных свойств канатных смазок не совсем корректно, так как происходит многократное завышение возможностей низкотемпературной стойкости смазочных материалов.

Это связано с тем, что во-первых, данный стандарт предназначен для испытаний низкотемпературных свойств битумов, в отличие от п. 3.5. ГОСТ 20458-89,

Табл. 1. Низкотемпературные свойства канатных СМ.

Table 1. Low-temperature properties of rope lubricant.

\begin{tabular}{|c|c|c|c|c|c|c|c|c|c|}
\hline \multirow[b]{2}{*}{ № } & \multirow[b]{2}{*}{$\begin{array}{l}\text { Показатель, метод испытаний } \\
\text { Indicator, test method }\end{array}$} & \multicolumn{8}{|c|}{ Смазочные материалы / Lubricants } \\
\hline & & $\begin{array}{c}\text { CM6 } \\
\text { L6 }\end{array}$ & $\begin{array}{c}\text { CM7 } \\
\text { L7 }\end{array}$ & $\begin{array}{c}\text { CM2 } \\
\text { L2 }\end{array}$ & $\begin{array}{c}\text { CM1 } \\
\text { L1 }\end{array}$ & $\begin{array}{c}\text { CM5 } \\
\text { L5 }\end{array}$ & $\begin{array}{c}\text { CM8 } \\
\text { L8 }\end{array}$ & $\begin{array}{c}\text { CM4 } \\
\text { L4 }\end{array}$ & $\begin{array}{c}\text { CM3 } \\
\text { L3 }\end{array}$ \\
\hline 1 & $\begin{array}{c}\text { Низкотемпературные свойства по ГОСТ } 20458 \text {, } \\
\text { выдерживает при температуре, }{ }^{\circ} \mathrm{C} \\
\text { Low-temperature properties in accordance with } \\
\text { GOST } 2045 \text {, withstands at a temperature, }{ }^{\circ} \mathrm{C}\end{array}$ & $>(-10)$ & -10 & -15 & -15 & -15 & -35 & -45 & -55 \\
\hline 2 & $\begin{array}{c}\text { Температура хрупкости по Фраасу ГОСТ 11507, } \\
\text { стандарт EN } 12593,{ }^{\circ} \mathrm{C} \text { фактически } \\
\text { Brittleness temperature according to Fraas } \\
\text { GOST } 11507, \text { EN } 12593,{ }^{\circ} \mathrm{C} \text { actual }\end{array}$ & -30 & -40 & $-(58-59)$ & -61 & -61 & $<(-65)$ & -67 & $<(-65)$ \\
\hline
\end{tabular}


который разрабатывался для испытаний низкотемпературных свойств канатной смазки, предназначенной для смазывания канатов, эксплуатирующихся в районах крайнего севера и в авиации. Во-вторых, методика испытаний по европейскому стандарту предусматривает статическое нагружение пленки образца, нанесенного на стальную пластинку при ее изгибе, а по российскому стандарту, предусматривается ударное нагружение образца, что, по мнению авторов, ближе к реальным условиям эксплуатации канатов.

В лабораториях технопарка была разработана методика испытания канатов на износостойкость [17], согласно которой испытания проводятся на пробежной машине в соответствии с ГОСТ 2387-80 «Канаты стальные. Метод испытаний на выносливость» [18]. При этом пробежная машина устанавливается в климатическую камеру, в которой поддерживается заданная температура (Рис. 1).

Испытания проводили с использованием каната марки 5.6-Г-І-Н-Р-1770, изготовленного по ГОСТ 2688-80. При его изготовлении пряди, сердечник, межпрядные и межпроволочные пространства не смазывались и не пропитывались смазочным материалом. Нарезанные из бухты образцы канатов диаметром 5.6 мм и длиной 4200 мм пропитывалась смазочным материалом методом окунания, при температуре на $20^{\circ} \mathrm{C}$ выше температуры каплепадения СМ в течение двух часов с последующей выдержкой на воздухе при температуре $\left(20 \pm 5^{\circ} \mathrm{C}\right)$ не менее 24 часов.

Скорость вращения барабана составляла 120 колебаний в минуту, при этом обеспечивались возвратнопоступательное перемещение образца на длине 350 мм. Нагрузка на одну ветвь каната составляла 245 Н. Сменные ролики диаметром 55 мм обеспечивали изгиб образца

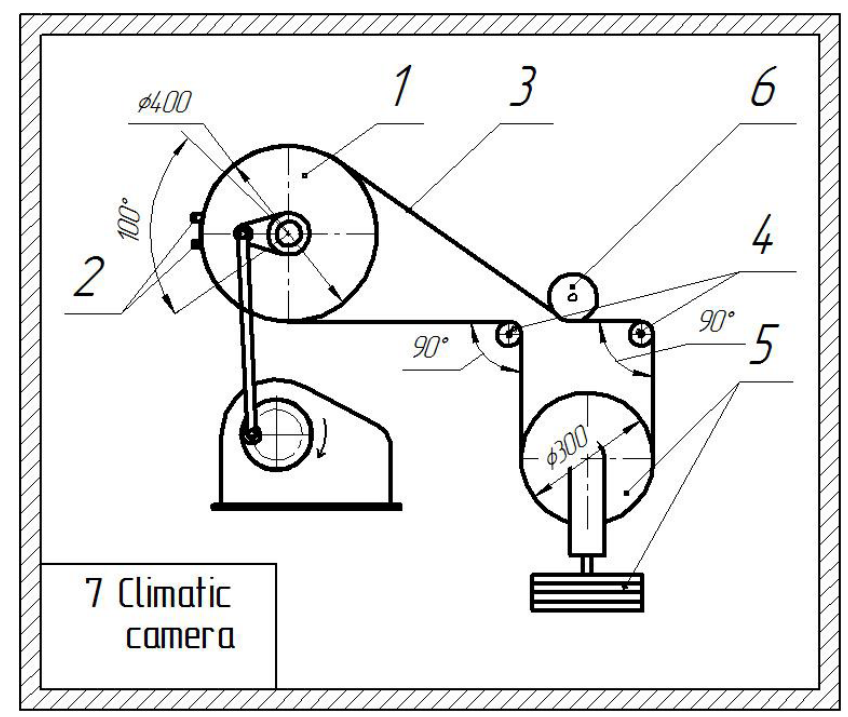

Рис. 1. Схема испытаний канатов на выносливость: 1 - ведущий барабан, 2 - зажимы для крепления образца каната, 3 - образец каната, 4 - сменные ролики, 5 - грузовой ролик, 6 - направляющий ролик, 7 - климатическая камера.

Fig. 1. Scheme of endurance testing of ropes: 1 - leading drum, 2 - clamps for fastening a rope sample, 3 - rope sample, 4 - interchangeable rollers, 5 - load roller, 6 - guide roller, 7 - climatic camera. на $90^{\circ}$. Диаметр сменных роликов и нагрузка на одну ветвь каната выбирались в зависимости от диаметра каната по ГОСТ 2172-80 «Канаты стальные авиационные. Технические условия» [19]. Износостойкость стального каната оценивалась по количеству перегибов образца каната до его полного разрушения.

Так же, как и в работе [20] выбор смазочных материалов для испытаний производился из отечественных и зарубежных образцов, применяющихся на российских предприятиях - производителях канатов, и полностью соответствующих требованиям нормативно-технической документации. Сохранена и нумерация канатных СM, используемая в указанной работе. Учитывая большой разброс результатов испытаний, характерных для усталостных испытаний, испытывались по 15 образцов каната, пропитанного каждой из отобранных канатных СM.

Первая серия испытаний проводилась при температуре окружающего воздуха в помещении от +15 до $+25^{\circ} \mathrm{C}$. Вторая серия испытаний проводилась в климатической камере при температуре окружающего воздуха $-60 \pm 2^{\circ} \mathrm{C}$. Результаты испытаний приведены на диаграмме (Рис. 2).

Статистическая обработка проводилась по ГОСТ Р. 8.736-2011 при доверительной вероятности 0.95 .

На примере CM6 (L6) хорошо видно, что использование такого смазочного материала при изготовлении каната повышает износостойкость каната при положительных температурах по отношению к не смазанному канату в 2.2 раза, а при температуре $-60^{\circ} \mathrm{C}$ износостойкость каната, пропитанного этим СМ, ниже чем у несмазанного (сухого) каната.

При проведении испытаний отмечалось, что СМ, имеющие неудовлетворительные низкотемпературные свойства, при испытаниях по ГОСТ 20458-89, в климатической камере при температуре $-60^{\circ} \mathrm{C}$, при первых же изгибах на роликах начинают осыпаться с поверхности каната (Рис. 3 a). Аналогичную картину авторы наблюдали при исследовании причин рекламации, полученной российским предприятием-производителем канатов. На Рис. 3 b показана бухта каната, на которой некачественная смазка осыпалась с поверхности в процессе ее транспортировки автомобильным транспортом при температуре окружающего воздуха не ниже $-20^{\circ} \mathrm{C}$ еще до начала эксплуатации.

Результаты испытаний, показывают, что СМ, оставшийся в межпрядном, в межпроволочном пространствах и в сердечнике каната, при низких температурах может кристаллизоваться и переставать выполнять основную функцию, заключающуюся в уменьшении трения и износа между поверхностями проволок, и способствовать абразивному износу. Так, канат, пропитанный CM6 (L6) полностью разрушился в течение меньшего количества циклов изгибов при испытаниях по отношению к испытаниям сухого (несмазанного) каната.

Таким образом, можно заявить, что назначение температурного диапазона применения каната необходимо производить с учетом низкотемпературных свойств канатного СМ, использованного при его изготовлении, определяемых в соответствии с п. 3.5. ГОСТ 20458-89. 


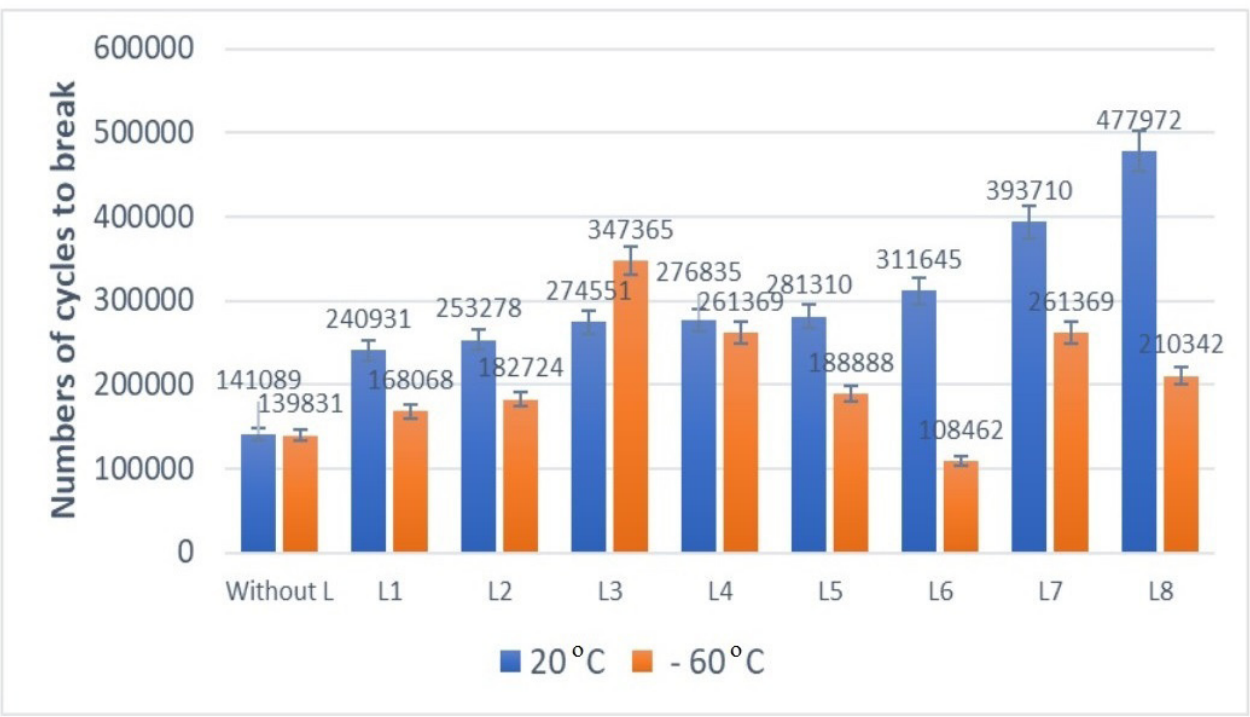

Puc. 2. (Color online) Выносливость канатов в испытаниях при комнатной температуре и при $-60^{\circ} \mathrm{C}$.

Fig. 2. (Color online) Endurance of the ropes in tests at room temperature and at $-60^{\circ} \mathrm{C}$.

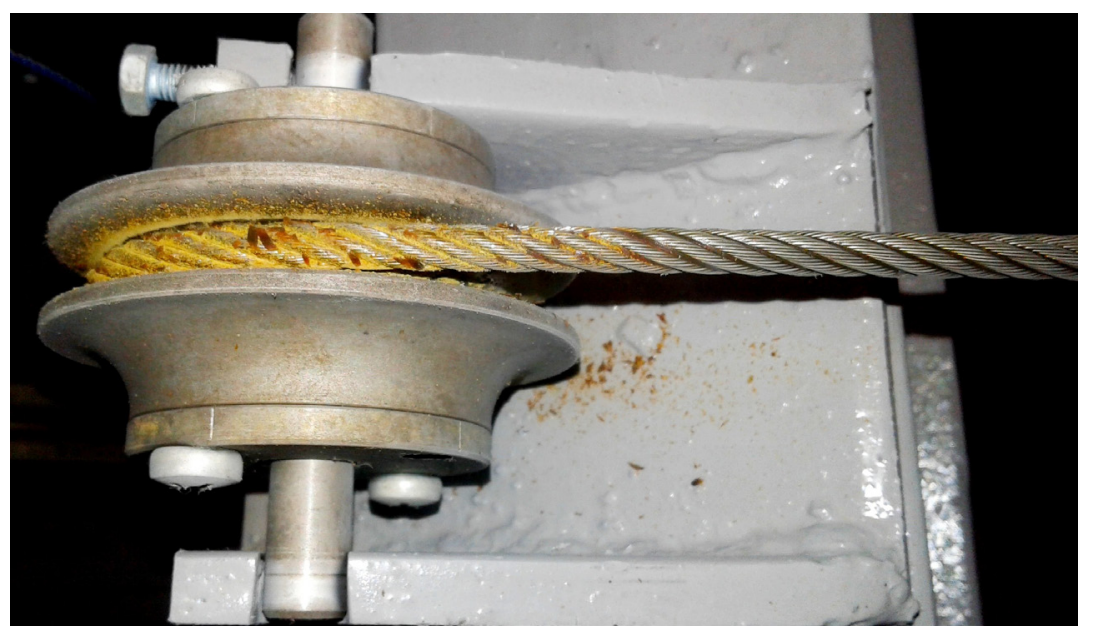

a

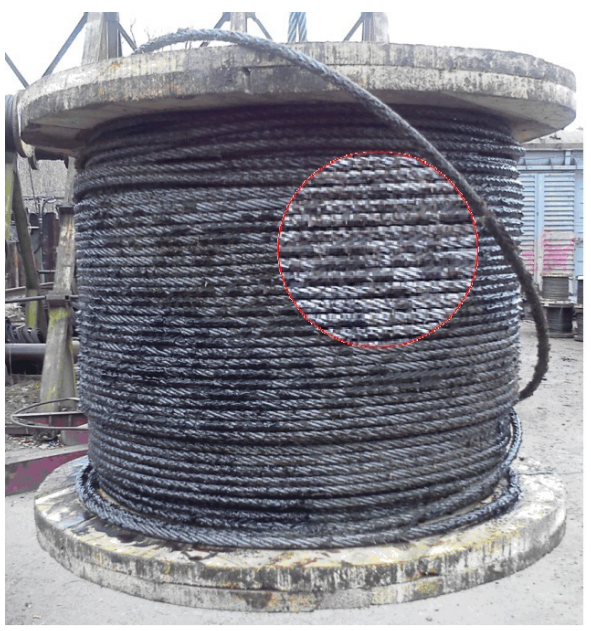

$\mathrm{b}$

Pис. 3. (Color online) Осыпание смазки с поверхности каната в начале проведения испытаний на пробежной машине (а), отслаивание и осыпание смазки с поверхности каната в процессе транспортировки при пониженных температурах (b).

Fig. 3. (Color online) Scattering lubricant from the surface of the rope at the beginning of the tests on the run machine (a), peeling and sprinkling of grease from the surface of the rope during transportation at low temperatures (b).

Использование для этих целей метода испытаний, предусмотренного ГОСТ 11507-78 или EN 12593:2007 может привести к существенному неоправданному сокращению срока службы каната.

\section{Выводы}

Настоящие исследования дают возможность утверждать:

1. Максимальный эффект по повышению износостойкости (ресурса) каната при низких температурах дают смазочные материалы, имеющие наилучшие низкотемпературные свойства, определенные по п. 3.5 ГОСТ 20458-89, что подтверждается полной корреляцией сравнительных результатов испытаний низкотемпературных свойств и износостойкости каната при низких температурах.
2. Можно предположить, что при низких температурах компоненты СМ кристаллизуются, образующиеся кристаллы выполняют роль абразивного элемента, способствующего ускоренному абразивному износу поверхностей проволок.

\section{Литература/References}

1. I. I. Markhel. Crane ropes. Moscow, Mashinostroenie (1983) 128 р. (in Russian) [И.И. Мархель. Крановые канаты. Москва, Машиностроение (1983) 128 с.]

2. L.M. Shkolnik. Fatigue Testing Technique. Moscow, Metallurgiya (1978) 304 p. (in Russian) [Л. М. Школьник. Методика усталостных испытаний. Москва, Металлургия (1978) 304 с.]

3. W. S. Utting, N. Jones. Int. J. Mech. Sci. 29, 605 (1987). Crossref 
4. D. Elata, R. Eshkenazy, M.P. Weiss. Int. J. Solids Struct. 41, 1157 (2004). Crossref

5. H. Usabiaga, J. M. Pagalday. Int. J. Solids Struct. 45, 5503 (2008). Crossref

6. A.N. Abramov, V.Yu. Sholom, O.L. Kramer, V.P. Golovin. Letters on Materials. 10 (2), 195 (2020). (in Russian) [А.Н. Абрамов, В. Ю Шолом, О.Л. Крамер, В.П. Головин. Письма о материалах. 10 (2), 195 (2020).] Crossref

7. M.P. Alexandrov, L.N. Kolobov, N.A. Lobov. Hoisting - transport machines and equipment. Moscow, Mashinostroyenie (1986) 400 p. (in Russian) [М.П. Александров, Л.Н. Колобов, Н.А. Лобов. Подъемно - транспортные машины и оборудование. Москва, Машиностроение (1986) 400 с.]

8. GOST 20458-89 “Grease Torsioll-55. Specifications». Moscow, IPC Standards Publishing (2002). (in Russian) [ГОСТ 20458-89 «Смазка Торсиол-55. Технические условия». Москва, ИПК Издательство стандартов (2002).]

9. K. Feyrer. Wire Ropes. Berlin-Heidelberg, Springer Verlag (2007) 322 p. $\underline{\text { Crossref }}$

10. C.R. Chaplin. J. of the Inst. of Mining Electrical and Mechanical Engineers. 76, 213 (1994).

11. S. A. Velinsky, G. L. Anderson, G. A. Costello. J. Eng. Mech. 110, 380 (1984). Crossref

12. A. Cardou, C. Jolicoeur. Appl. Mech. Rev. 50, 1 (1997). Crossref
13. C. R. Chaplin. OIPEEC Bulletin. 70, 31 (1995).

14. M. A. Urchegui, W. Tato, X. Gomez. J. Mat. Eng. Perform. 17, 550 (2008). Crossref

15. M. Giglio, A. Manes. Eng. Fail. Anal. 12, 549 (2005). Crossref

16. EN 12593:2007 Bitumen and bituminous binders Determination of the Fraass breaking poin.

17. Patent RF № 2640319. 27.12.2017. (in Russian) [Патент РФ № 2444719, 27.12.2017.]

18. GOST 2387-80 «Steel ropes. Endurance Test Method» Moscow, Publishing house of standards (1980). (in Russian) [ГОСТ 2387-80 «Канаты стальные. Метод испытания на выносливость». Москва, Издательство стандартов (1980).]

19. GOST 2172-80 "Steel aviation ropes. Technical conditions" Moscow, Publishing house of standards (1980). (in Russian) [ГОСТ 2172-80 «Канаты стальные авиационные. Технические условия». Москва, Издательство стандартов (1980).]

20. V. P. Golovin, V. Yu. Sholom, A. N. Abramov, O. L. Kramer, O. P. Kornilova. All-Russian Congress on Fundamental Problems of Theoretical and Applied Mechanics: Works Collection: Symposium Materials. Ufa. 4, 507 (2019). (in Russian) [В.П. Головин, В. Ю. Шолом, А.Н. Абрамов, О.Л. Крамер, О.П. Корнилова. XII Всероссийский съездпо фундаментальнымпроблемам теоретической и прикладной механики: сборник трудов: Материалы симпозиумов. Уфа. 4, 507 (2019).] $\underline{\text { Crossref }}$ 